Check for updates

Cite this: J. Mater. Chem. A, 2019, 7, 2795

Received 30th November 2018 Accepted 7th January 2019

DOI: $10.1039 / c 8 t a 11534 f$

rsc.li/materials-a

\section{Physical pinning and chemical crosslinking- induced relaxor ferroelectric behavior in P(VDF-ter-TrFE-ter-VA) terpolymers $\uparrow$}

\author{
Niels L. Meereboer, (D) Ivan Terzić, Piet van der Steeg, Giuseppe Portale (D) \\ and Katja Loos iD *
}

Relaxor ferroelectric polymers, having a high energy storage density and efficiency, are rapidly developing for reliable and compact dielectric film capacitors. Until now, they have been based on highly fluorinated monomers lacking functionalities for further modifications, such as good dispersion of nanoparticles or facile crosslinking, to gain enhanced properties. In this work, we study the electroactive properties of a novel class of poly(vinylidene fluoride-ter-trifluoroethylene-tervinyl alcohol) (P(VDF-ter-TrFE-ter-VA)) terpolymers for capacitive energy storage applications. Additionally, we show that the VA units in these terpolymers can be crosslinked using facile urethane chemistry. It is found that introducing VA in the terpolymer backbone leads to cocrystallization with the fluorinated monomeric constituents. The VA defects promote the formation of TTTG monomer sequences favoring relaxor ferroelectric behavior. Consequently, the Curie transition is strongly reduced compared to P(VDF-co-TrFE) analogues. Moreover, chemical crosslinking of P(VDF-terTrFE-ter-VA) terpolymers results in extremely slim hysteresis loops due to the increase in the relative amount of the disordered paraelectric phase and ultrafine crystallites. Therefore, this new class of relaxor ferroelectric polymers, wherein physical pinning and chemical crosslinking are combined, shows great promise for future advanced applications.

\section{Introduction}

Advanced electronic devices and circuits, pulsed power technologies and electric vehicles are among others applications that need high energy density dielectrics for capacitive energy storage. ${ }^{1-3}$ Nowadays, by selecting polymers as the material of choice, main requirements such as lightweight, low cost, ease of processing, self-healing capability and high breakdown strengths are easily fulfilled. Unfortunately, inherent to commercially available high breakdown strength polymers are low dielectric constants, suppressing the maximum energy densities in order to be stored inside dielectrics. For instance, state-of-the-art BOPP shows an energy density of $4 \mathrm{~J} \mathrm{~cm}^{-3}$ at an electric field of $600 \mathrm{MV} \mathrm{m}^{-1}$. Therefore, to improve the energy storage in dielectrics, they require both a high dielectric constant $(\varepsilon)$ and high breakdown strength, since the stored energy density $(U)$ is proportional to the dielectric constant and the electric

Macromolecular Chemistry and New Polymeric Materials, Zernike Institute for Advanced Materials, University of Groningen, Nijenborgh 4, 9747 AG Groningen, The Netherlands.E-mail: k.u.loos@rug.nl

$\dagger$ Electronic supplementary information (ESI) available. See DOI: $10.1039 / \mathrm{c} 8 \mathrm{ta} 11534 \mathrm{f}$ field $(E)$ squared as displayed in eqn (1), wherein $\varepsilon_{0}$ is the permittivity in free space.

$$
U=\frac{1}{2} k \varepsilon_{0} E^{2}
$$

In contrast, poly(vinylidene fluoride) (PVDF) has both a high dielectric constant $(\sim 10)$ and breakdown strength $\left(\sim 600 \mathrm{MV} \mathrm{m}^{-1}\right)$, making it an excellent choice to be used as a dielectric material. ${ }^{\mathbf{4}, 5}$ However, an irreversible crystalline phase transformation from the $\alpha$ - to the ferroelectric $\beta$-phase at high electric fields results in ferroelectric behavior, which suffers from large hysteresis losses. ${ }^{6}$ Accordingly, current research efforts focus on tuning the crystal phase, crystallite size and crystalline-amorphous interface of PVDF-based (co)polymers to yield slim hysteresis loops (i.e. relaxor or double hysteresis loop (DHL) behavior) while still having large polarizations. ${ }^{5,7-15}$

As such, co- and terpolymerizations of VDF with other fluorinated comonomers, like trifluoroethylene (TrFE), chlorotrifluoroethylene (CTFE) and chlorofluoroethylene (CFE), have been employed to gradually increase the crystal lattice spacing. ${ }^{16,17}$ Dependent on the processing conditions, incorporating these comonomers with a lower dipole moment leads to the formation of physical pinning spots, destabilizing the ferroelectric phase and enhancing the dipole reversibility, 
which results in relaxor ferroelectric behavior. Moreover, in a P(VDF-ter-TrFE-ter-CTFE) terpolymer, a specific monomer composition leads to a near room temperature Curie transition accompanied with large dielectric constants $(\varepsilon=50)$, rendering these materials suitable for electrocaloric cooling devices as well. ${ }^{18,19}$ Interestingly, the Wang group revealed that tacticity in $\mathrm{P}(\mathrm{VDF}-\mathrm{co}$-TrFE) copolymers plays a crucial role in their electroactive behavior. ${ }^{20}$ Here, stereochemical changes (from mainly syndiotactic to isotactic sequences) induced by stereospecific TrFE monomers leads to an order-to-disorder evolution in the crystalline phase at $>45 \mathrm{~mol} \%$ TrFE, which results in an increasing amount of $3 / 1$ helices as opposed to all-trans planar conformations - changing their behavior from ferroelectric to relaxor ferroelectric behavior. ${ }^{20}$ Additionally, after mechanical stretching, bulky hexafluoropropylene (HFP) monomeric constituents are incorporated in the polymer crystals leading to relaxor ferroelectric behavior, which is caused by a break up of large ferroelectric nanodomains into smaller nonpolar regions. ${ }^{21} \mathrm{P}(\mathrm{VDF}-\mathrm{co}$-CTFE) copolymers grafted with polystyrene (PS) or poly(alkyl methacrylate) (PAMA) are another means to avert ferroelectric behavior in PVDF. ${ }^{7,22,23}$ Here, PS or PAMA side chains segregate to the crystalline-amorphous interface, creating a nonpolar confining layer that effectively destabilizes the ferroelectric domains, resulting in DHL behavior. These strategies change the electroactive behavior of PVDF drastically and show increased released energy densities and efficiencies.

Alternative strategies to modify PVDF to obtain dielectric materials include chemical crosslinking. In this way, small nanocrystals are formed while additionally increasing the dielectric breakdown strength of the material due to an enhancement of the mechanical properties. ${ }^{24,25}$ Unfortunately, effective means to gain control over the crosslinking sites in fluorinated polymers are rare due to the lack of functionalities in fluorinated backbones. Nevertheless, chemical crosslinking is performed using peroxides and triallyl isocyanurate (TI), diamines or electron beam irradiation. ${ }^{24,26,27}$ In particular, the use of peroxides and TI to crosslink $\mathrm{P}(\mathrm{VDF}-\mathrm{co}$-CTFE) results in excellent dielectric performance having high efficiencies and large released energy densities $\left(83 \%\right.$ and $17 \mathrm{~J} \mathrm{~cm}^{-3}$ at $400 \mathrm{MV}$ $\mathrm{m}^{-1}$, respectively), showing the great potential of chemically crosslinked PVDF for capacitive energy storage applications.

Recently, we have shown how vinyl alcohol (VA) units can easily be introduced in the PVDF backbone. ${ }^{28}$ Due to the small size of the monomeric units, they can be included in PVDF crystals, increasing the crystal lattice size and acting as pinning spots. Moreover, these hydroxyl functionalities, being well distributed over the polymer backbone, can be used to perform easy additional chemistries to improve, for example, nanoobject dispersion, adhesion to interfaces, and crosslinking. In this work, physical pinning and chemical crosslinking are combined. We demonstrate the synthesis and chemical crosslinking of $\mathrm{P}(\mathrm{VDF}-$ ter-TrFE-ter-VA) terpolymers and show their electroactive behavior. In addition, the effect of VA units on the thermal behavior (Curie transition, crystallization and melting temperatures) in the terpolymers is investigated. It is found that the Curie transition temperature of $\mathrm{P}$ (VDF-ter-TrFE-ter-VA) terpolymers is strongly reduced. Moreover, the crosslinked materials display narrow hysteresis loop relaxor ferroelectric behavior, making them highly suitable for capacitive energy storage applications.

\section{Materials and methods}

\section{Materials}

Benzoyl peroxide was recrystallized prior to use. Vinyl acetate was dried over $\mathrm{CaH}_{2}$ and distilled under reduced pressure. Vinylidene fluoride (VDF, SynQuest Labs, 98\%), trifluoroethylene (TrFE, SynQuest Labs, 98\%), hexamethylenediisocyanate (HMDI, TCI, 98\%) and cyclopentanone (TCI, >99\%) were used as received. All solvents were obtained from commercial resources and used without further purification.

\section{Experimental}

\section{Synthesis of $\mathrm{P}(\mathrm{VDF}-$ ter-TrFE-ter-VAc) terpolymers}

A $600 \mathrm{~mL}$ Parr (model 4568) high pressure reactor was charged with benzoyl peroxide (150 $\mathrm{mg}, 0.62 \mathrm{mmol})$, anhydrous dimethyl carbonate $(300 \mathrm{~mL})$, and freshly distilled vinyl acetate (VAc, $1 \mathrm{~mL}, 10.9 \mathrm{mmol}$ ). After the reaction mixture was purged with $\mathrm{N}_{2}$ for $30 \mathrm{~min}$, TrFE (2.5 bar) and VDF (to 15 bar) were transferred into a reactor at room temperature. The reaction mixture was rapidly heated to $90{ }^{\circ} \mathrm{C}$ and allowed to stir at $500 \mathrm{rpm}$ for $30 \mathrm{~min}$. Subsequently, the heating source was removed and the reaction mixture was cooled to room temperature using a water flow. Excess of TrFE and VDF was removed by depressurizing the reaction vessel. The solution was concentrated in vacuo in order to precipitate the terpolymer in a water/methanol mixture. Excess of initiator was removed by extensively washing with chloroform. Finally, the terpolymer was dried in a vacuum.

\section{Synthesis of P(VDF-ter-TrFE-ter-VA) terpolymers}

A general synthetic procedure is described as follows: a roundbottom flask was charged with 1.0 gram of $\mathrm{P}(\mathrm{VDF}-$ ter-TrFE-terVAc) terpolymers, dioxane $(80 \mathrm{~mL})$, and concentrated hydrochloric acid $(8 \mathrm{~mL})$. The reaction mixture was stirred overnight at $60{ }^{\circ} \mathrm{C}$. The mixture was concentrated in vacuo, from where the terpolymer was precipitated by adding a large excess of water. Subsequently, the copolymer was collected via filtration followed by extensive washing with water to remove residual side products and hydrochloric acid. The terpolymers were finally precipitated in cold pentane, yielding $\sim 0.8$ grams of white $\mathrm{P}(\mathrm{VDF}-$ ter-TrFE-ter-VA) terpolymers.

\section{Crosslinking of P(VDF-ter-TrFE-ter-VA) terpolymers}

$\mathrm{P}($ VDF-ter-TrFE-ter-VA) $(25 \mathrm{mg}, 36.0 \mu \mathrm{mol} \mathrm{VA})$ and HMDI $(0.5 \times$, $1.44 \mu \mathrm{L}, 9.0 \mu \mathrm{mol} ; 0.25 \times, 0.72 \mu \mathrm{mol} ; 0.1 \times, 1.8 \mu \mathrm{mol}, 0.29 \mu \mathrm{L})$ were combined in a total volume of $1.5 \mathrm{~mL}$ cyclopentanone and allowed to mix at $80{ }^{\circ} \mathrm{C}$ for $30 \mathrm{~min}$. After cooling down to room temperature, the solution was passed through a $0.45 \mu \mathrm{m}$ PTFE filter into an aluminum pan (ø $3 \mathrm{~mm})$. Pristine P(VDF-ter-TrFEter-VA) terpolymers were, after dissolving in cyclopentanone (40 $\mathrm{mg}$ in $1.5 \mathrm{~mL}$ ), directly transferred to an aluminum pan 
using a $0.45 \mu \mathrm{m}$ PTFE filter. The aluminum pan was put on a heating plate set at $130{ }^{\circ} \mathrm{C}$ to induce crosslinking and evaporation of solvent. The next day, the (crosslinked) samples were heated to $160{ }^{\circ} \mathrm{C}$ to erase thermal history and subsequently quenched at room temperature. Subsequently, $\sim 10 \mu \mathrm{m}$ thick free-standing films are obtained via a lift-off method in water. All samples were dried overnight under vacuum.

\section{Characterization}

\section{NMR spectroscopy}

${ }^{1} \mathrm{H}$ and ${ }^{19} \mathrm{~F}$ NMR (COSY) spectra were recorded on a Varian (VXR) spectrometer operating at $400 \mathrm{MHz}$ for the ${ }^{1} \mathrm{H}$ nucleus and $376 \mathrm{MHz}$ for the ${ }^{19} \mathrm{~F}$ nucleus. The composition is determined via the following method. First, the ratio between VDF and TrFE $\left(r_{\mathrm{VDF} / \mathrm{TrFE}}\right)$ is calculated using ${ }^{19} \mathrm{~F}$ NMR spectroscopy. ${ }^{20}$ The ratio of TrFE and VA is determined using ${ }^{1} \mathrm{H}$ NMR spectroscopy according to the following equation:

$$
r_{\mathrm{TrFE} / \mathrm{VA}}=\frac{\int_{5.10}^{6.00} \mathrm{CH}_{\mathrm{TrFE}}}{\left(\left(\int_{4.11}^{5.00} \mathrm{CH}_{\mathrm{VA}}+\mathrm{OH}_{\mathrm{VA}}\right) / 2\right)}
$$

Consequently, using the ratios $r_{\mathrm{VDF} / \mathrm{TrFE}}$ and $r_{\mathrm{TrFE} / \mathrm{VA}}$, the terpolymer composition is obtained.

\section{Fourier transform infrared spectroscopy}

The FTIR spectra of the copolymers were recorded on a Bruker Vertex 70 spectrophotometer using 32 scans at a nominal resolution of $4 \mathrm{~cm}^{-1}$ using a diamond single reflection attenuated total reflectance (ATR).

\section{Differential scanning calorimetry (DSC)}

DSC thermograms were recorded on a TA Instruments DSC Q1000. The heating and cooling rates were set to be $10{ }^{\circ} \mathrm{C} \mathrm{min}^{-1}$.

\section{Wide-angle X-ray scattering (WAXS)}

WAXS measurements were performed at the beamline BM26B at the European Synchrotron Radiation Facility (ESRF) in Grenoble with a wavelength $\lambda=0.97 \AA^{.29,30}$ The WAXS patterns were acquired using a Pilatus $300 \mathrm{~K}$ detector with $1472 \times 195$ pixels of $172 \mu \mathrm{m} \times 172 \mu \mathrm{m}$ placed at a distance of $0.28 \mathrm{~m}$ and using an exposure time of $30 \mathrm{~s}$. The scattering vector $q$ is defined as $q=$ $4 \pi / \lambda(\sin \theta)$ with $2 \theta$ being the scattering angle. The scattering angle scale was calibrated using the known peak positions from a standard alpha $\mathrm{Al}_{2} \mathrm{O}_{3}$ powder. Deconvolution of the WAXS profiles was achieved using a MATLAB script. The experimental profiles were deconvoluted by using the sum of a linear background and pseudo-Voigt peaks describing the scattering from the amorphous and crystalline phases.

\section{Electrical characterization}

D-E and I-E loops were obtained using a state-of-the-art aixACCT TF2000E ferroelectric tester where AC electric fields (up to
$10 \mathrm{kV}$ ) were applied across the polymer films with a triangular waveform at a frequency of $10 \mathrm{~Hz}$. Chromium (5 nm)/gold (100 $\mathrm{nm}$ ) electrodes with a diameter of $2 \mathrm{~mm}$ were deposited on both sides of $\mathrm{P}(\mathrm{VDF}$-ter-TrFE-ter-VA) terpolymer films by vapor deposition. Chromium was used only as the adhesion layer. Silicon oil was used to prevent flashovers.

\section{Results and discussion}

The synthesis and crosslinking of $\mathrm{P}(\mathrm{VDF}-$ ter-TrFE-ter-VA) terpolymers are outlined in Scheme 1.

To study the impact of the introduction of VA units in the $\mathrm{P}(\mathrm{VDF}-\mathrm{ter}$-TrFE-ter-VA) terpolymers on the thermal and electroactive behavior, we synthesized two different terpolymers having a similar TrFE/VA ratio, $\mathrm{P}\left(\mathrm{VDF}_{0.78}\right.$-ter-TrFE ${ }_{0.17}$-ter- $\left.\mathrm{VA}_{0.05}\right)$ and $\mathrm{P}\left(\mathrm{VDF}_{0.53}\right.$-ter-TrFE ${ }_{0.37}$-ter-VA $\left.\mathrm{VA}_{0.10}\right)$. Since $\mathrm{P}(\mathrm{VDF}-\mathrm{co}-\mathrm{TrFE})$ copolymers containing 50 or $80 \mathrm{~mol} \% \mathrm{VDF}$ are on the verge of solely crystallizing in the ferroelectric phase, replacing TrFE units with VA, while having a similar amount of VDF, allows for a good comparison to literature reports. ${ }^{20,31}$

Because the tautomerization equilibrium of vinyl alcohol lies on the acetaldehyde side, $\mathrm{P}(\mathrm{VDF}-$ ter-TrFE-ter-VA) is synthesized indirectly using vinyl acetate (VAc) in the terpolymerization
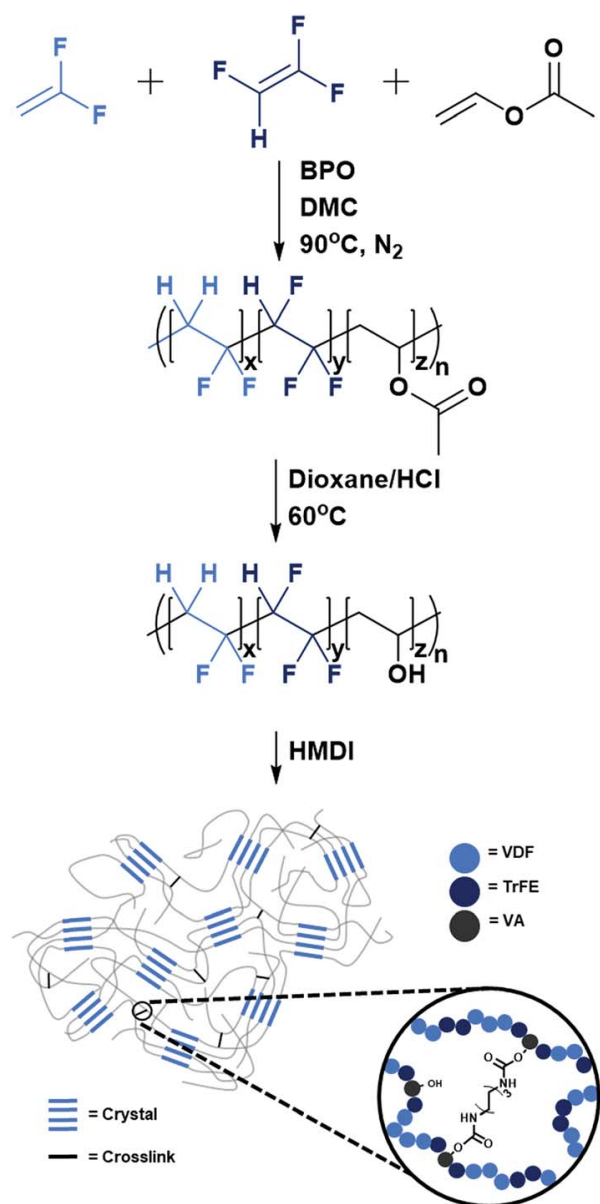

Scheme 1 Synthetic approach towards chemically crosslinked P(VDF-ter-TrFE-ter-VA) terpolymers. 
reaction..$^{32}$ As such, via a free radical polymerization, VDF, TrFE and VAc are terpolymerized in dimethyl carbonate (DMC) using benzoyl peroxide (BPO) as the initiator. DMC is selected as the solvent due to a good trade-off between the reaction rate and chain transfer to the solvent. ${ }^{33}$ It is understood from the literature that terpolymerizations of vinyl monomers, such as 3,3,3trifluoropropene (TFP), with VDF and TrFE lead to compositional heterogeneity when high conversions are achieved as TFP prefers to homopropagate due to large differences in reactivity ratios. ${ }^{34}$ To mitigate concerns regarding compositional heterogeneity, the reaction times are kept short (with minimal pressure drop $<2$ bar to prevent large variations in VDF and TrFE concentrations) and the VAc content is kept low to minimize the compositional drift due to the large differences in reactivity ratios between VDF and VAc leading to the preferential consumption of VAc during the polymerization. ${ }^{28,35,36}$ After the polymerization, the presence of unreacted VAc is confirmed by ${ }^{1} \mathrm{H}$ NMR spectroscopy indicating that no $\mathrm{P}(\mathrm{VDF}-c o-\mathrm{TrFE})$ copolymers are formed. Subsequently, hydrolysis of the P(VDFter-TrFE-ter-VAc) terpolymers in a dioxane/ $\mathrm{HCl}$ mixture yields $\mathrm{P}$ (VDF-ter-TrFE-ter-VA). Noteworthily, acidic conditions are used to hydrolyze the terpolymers to prevent dehydrofluorination reactions.

In Fig. 1, the ${ }^{1} \mathrm{H}$ NMR spectra demonstrate the complete removal of the acetyl group by the disappearance of the corresponding methyl protons located at $2.00 \mathrm{ppm}$, proving a successful full conversion to the hydroxyl functionalized terpolymers. Additionally, an upfield shift of the methine protons $(-\mathrm{C} \underline{H}(\mathrm{OH})-)$ to $4.11-4.60 \mathrm{ppm}$ confirms the formation of hydroxyl groups, in which protons are located between 4.11 and $5.00 \mathrm{ppm}$. Moreover, the multiple correlation signals in the ${ }^{1} \mathrm{H}$ NMR correlation spectrum (Fig. S4 and S5†) reveal that the methine protons of the vinyl alcohol units correlate with different monomer sequences of both VDF ( $\left.-\mathrm{CH}_{2} \mathrm{CF}_{2}-, 2.26 \mathrm{ppm}\right)$ and $\mathrm{TrFE}\left(-\mathrm{C}_{\mathrm{H}} \mathrm{FCF}_{2^{-}}, 5.15,5.65,6.3\right.$ ppm), indicating the good distribution of VA units in the backbone. Previous work in our group already demonstrated the dispersion of VA units (up to $15 \mathrm{~mol} \%$ ) in $\mathrm{P}(\mathrm{VDF}-\mathrm{co}-\mathrm{VA})$ copolymers, where similar reaction conditions are applied. ${ }^{28}$ However, different from those of $\mathrm{P}(\mathrm{VDF}-c o$-VA) copolymers, the

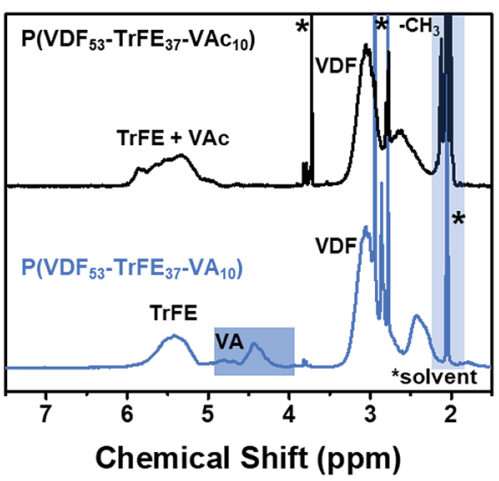

Fig. $1{ }^{1} \mathrm{H}$ NMR spectra of $\mathrm{P}\left(\mathrm{VDF}_{0.53}\right.$-ter-TrFE 0.37 -ter-VAc $\mathrm{C}_{0.10}$ ) (top) and $\mathrm{P}\left(\mathrm{VDF}_{0.53}\right.$-ter-TrFE $\mathrm{E}_{0.37}$-ter-VA $\mathrm{A}_{0.10}$ ) (bottom), showing the successful hydrolysis.
${ }^{1} \mathrm{H}$ NMR spectra (Fig. 1 and S1 $\dagger$ ) of the P(VDF-ter-TrFE-ter-VA) terpolymers show an additional signal that appears around $4.80 \mathrm{ppm}$. This is attributed to the $-\mathrm{OH}$ protons of VA units adjacent to TrFE units and the signal becomes more pronounced when the TrFE content in the terpolymer composition is increased, highlighting the difference of the microstructure between the two terpolymers used in this study. Here, the fluorine atom $\mathrm{TrFE}$ in $-\mathrm{CH}(\mathrm{OH}) \mathrm{C}_{1} \mathrm{FCF}_{2}{ }^{-}$causes more deshielding leading to a downfield shift compared to the hydroxyl group of VA next to a VDF unit. ${ }^{28}$ Since there is a clear distinction between the VA protons and the $-\underline{\mathrm{CH}} \mathrm{F}-$ protons corresponding to TrFE (5.10-6.00 ppm), the ratio between TrFE and VA can be easily determined. From the ${ }^{19} \mathrm{~F}$ NMR spectra (Fig. S2 and S3†), the ratio between VDF and TrFE is obtained, allowing the terpolymer composition to be calculated.

To examine the thermal characteristics of the terpolymers $\mathrm{P}\left(\mathrm{VDF}_{0.78}\right.$-ter-TrFE $\mathrm{T}_{0.17}$-ter- $\left.\mathrm{VA}_{0.05}\right)$ and $\mathrm{P}\left(\mathrm{VDF}_{0.53}\right.$-ter-TrFE $\mathrm{T}_{0.37}$-ter$\mathrm{VA}_{0.10}$ ), we performed differential scanning calorimetry (DSC) measurements. As shown in Fig. 2a, replacing TrFE units with VA in the polymer backbone has a profound influence on the thermal behavior of the terpolymers. ${ }^{20,37}$ The crystallization temperature $\left(T_{\text {cr }}\right)$ of $\mathrm{P}\left(\mathrm{VDF}_{0.78}\right.$ ter-TrFE $\mathrm{T}_{0.17}$-ter- $\left.\mathrm{VA}_{0.05}\right)$ is determined to be $93{ }^{\circ} \mathrm{C}$, while the Curie transition temperature $\left(T_{\mathrm{C}}\right)$ dropped to $55^{\circ} \mathrm{C}$, about $25^{\circ} \mathrm{C}$ lower than that of $\mathrm{P}(\mathrm{VDF}-\mathrm{co}$-TrFE) with an equal VDF/TrFE ratio. A similar behavior is observed in the melting scan. Here, a sharp Curie transition has a maximum at $79{ }^{\circ} \mathrm{C}$ and the polymer is completely molten at $120^{\circ} \mathrm{C}$, both values strongly reduced compared to those of $\mathrm{P}(\mathrm{VDF}-\mathrm{TrFE})$ with $22 \mathrm{~mol} \% \operatorname{TrFE}\left(T_{\mathrm{C}} \sim 100{ }^{\circ} \mathrm{C}\right.$ and $\left.T_{\mathrm{m}} \sim 148{ }^{\circ} \mathrm{C}\right) .{ }^{37} \mathrm{P}\left(\mathrm{VDF}_{0.53}\right.$-ter$\mathrm{TrFE}_{0.37}$-ter-VA $\mathrm{VA}_{0.10}$ ), containing less VDF and a comparable ratio of $\operatorname{TrFE} / \mathrm{VA}$, demonstrates a higher crystallization temperature than $\mathrm{P}\left(\mathrm{VDF}_{0.78}\right.$-ter-TrFE ${ }_{0.17}$-ter- $\left.\mathrm{VA}_{0.05}\right)$, whereas its Curie transition temperature is lowered to $40^{\circ} \mathrm{C}$. Upon heating, the reverse process involves a Curie transition at $46^{\circ} \mathrm{C}$ and the terpolymer is completely molten at $149{ }^{\circ} \mathrm{C}$. The large difference in the melting temperature of the terpolymers is analogous to that of $\mathrm{P}(\mathrm{VDF}-\mathrm{co}-\mathrm{TrFE})$ copolymers. Here, the $T_{m}$ takes a minimum value with $90 \mathrm{~mol} \% \mathrm{VDF}$ and is shifted to higher values when the VDF or TrFE content is increased, moving towards the $T_{\mathrm{m}}$ of its parent homopolymers. ${ }^{37}$ As expected, an increasing TrFE content in the terpolymers lowers the Curie transition temperature. Even though the Curie transition temperature of $\mathrm{P}(\mathrm{VDF}-\mathrm{co}-\mathrm{TrFE})$ copolymers can be slightly varied by tuning the processing conditions or polymerization method, our terpolymers show a $T_{\mathrm{C}}$ much lower than that obtained for $\mathrm{P}(\mathrm{VDF}-c o-\mathrm{TrFE})$ having a similar VDF content. ${ }^{38-40}$ This result is quite remarkable, since it is generally believed that monomers having a larger size (TrFE > VA) facilitate reducing the Curie transition temperature. ${ }^{8}$ In comparison, $\mathrm{P}(\mathrm{VDF}$-ter-TrFE-terCTFE) terpolymers, wherein CTFE also cocrystallizes with VDF and TrFE regardless of the melt crystallization conditions, also show a reduction in Curie transition when TrFE units are replaced by CTFE. ${ }^{19,41} \mathrm{~A}$ third monomer introduced into the polymer backbone acts as a defect allowing an increase in the crystal lattice spacing and more TTTG $^{+}{ }^{+} T_{T G}{ }^{-}$conformations ( $\mathrm{T}=$ trans and $\mathrm{G}=$ gauche), as opposed to the densely packed alltrans conformation in ferroelectric $\mathrm{P}(\mathrm{VDF}-c o-\mathrm{TrFE})$. This increase 

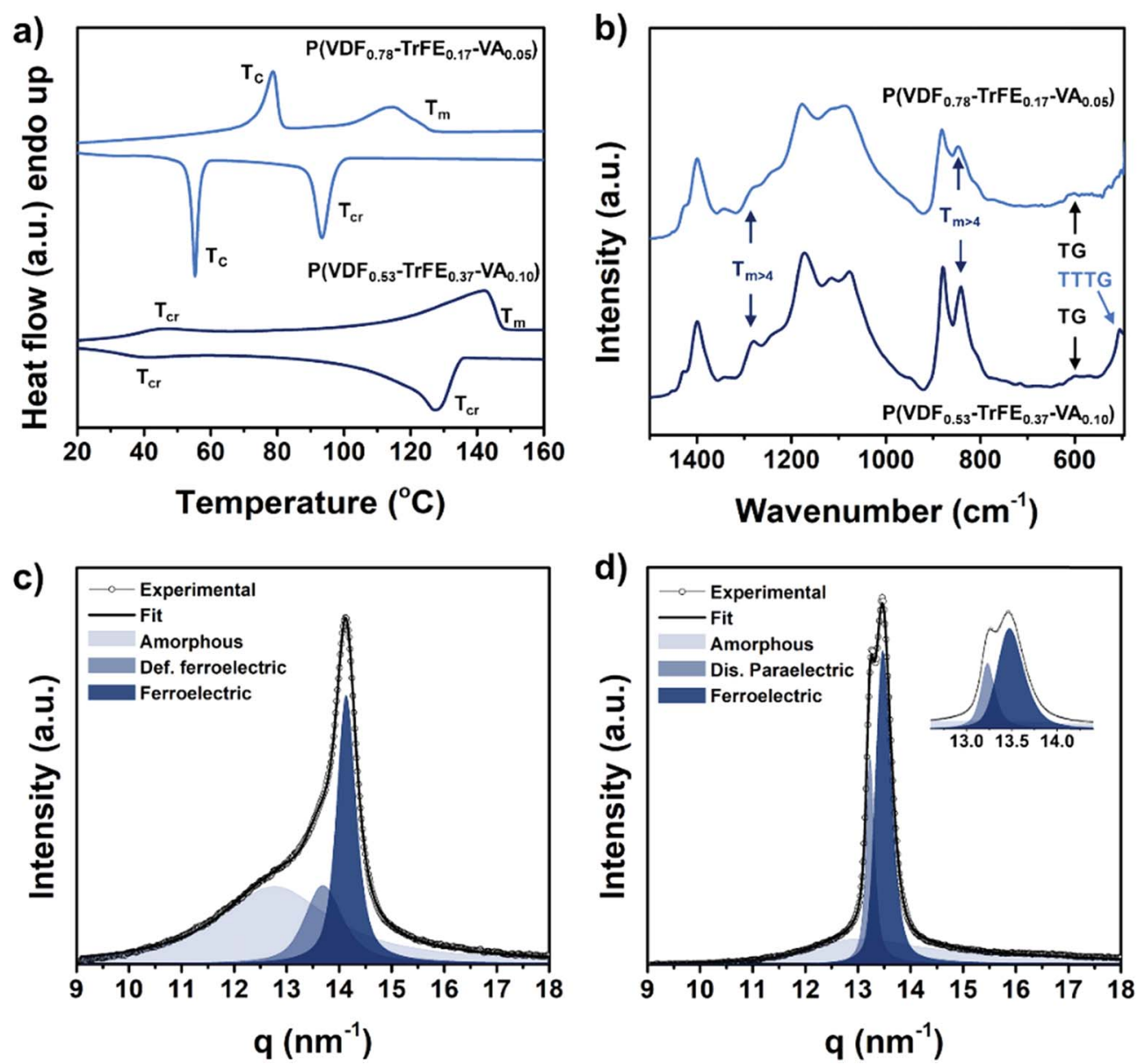

Fig. 2 (a) DSC thermograms and (b) FTIR spectra of the P(VDF-ter-TrFE-ter-VA) terpolymers. WAXS profiles of (c) P(VDF 0.78 -ter-TrFE 0.17 -ter$\left.V A_{0.05}\right)$ and (d) $P\left(V_{D F} F_{0.53}\right.$ ter-TrFE 0.37 -ter-VA $\left.\mathrm{A}_{0.10}\right)$.

in the disordered paraelectric phase content and the increased interchain distance in the crystals lower the required energy barrier for the Curie transition, leading to a room temperature phase transition for $\mathrm{P}\left(\mathrm{VDF}_{0.79}\right.$-ter-TrFE $\mathrm{T}_{0.07}$-ter- $\left.\mathrm{CTFE}_{0.14}\right)$.

To further elucidate the effect of VA incorporation in the terpolymer backbone on the crystallization behavior, Fourier transform infrared spectroscopy (FTIR) (Fig. 2b) and wide-angle X-ray scattering (WAXS) (Fig. 2c and d) were performed. Absorbance peaks belonging to the specific monomer conformations in the FTIR spectra are located around 507 (TTTG), 614 (TG), $840\left(\mathrm{~T}_{\mathrm{m}>4}\right)$ and $1280 \mathrm{~cm}^{-1}\left(\mathrm{~T}_{\mathrm{m}>4}\right){ }^{20,42}$ The $\mathrm{P}\left(\mathrm{VDF}_{0.53}\right.$-ter$\left.\operatorname{TrFE}_{0.37}-t e r-\mathrm{VA}_{0.10}\right)$ shows, next to the $\mathrm{T}_{\mathrm{m}>4}$ conformations, the characteristic TTTG and TG absorption bands at $506 \mathrm{~cm}^{-1}$ and $612 \mathrm{~cm}^{-1}$. Even though the absorption bands associated with the TTTG are absent in $\mathrm{P}\left(\mathrm{VDF}_{0.78}\right.$-ter-TrFE $\mathrm{E}_{0.17}$-ter- $\left.\mathrm{VA}_{0.05}\right)$, the peaks corresponding to the $\mathrm{T}_{\mathrm{m}>4}$ conformations are present albeit less intense just as the TG absorption bands. Interestingly, a recent study using ${ }^{19} \mathrm{~F}$ NMR spectroscopy and computational data show that isotactic TrFE-TrFE segments preferentially crystallize in a $3 / 1$ helical conformation having TTTG conformations. ${ }^{20,43}$ Indeed, comparing the ${ }^{19} \mathrm{~F}$ NMR spectra of the VA-based terpolymers used in this study, $\mathrm{P}\left(\mathrm{VDF}_{0.53}\right.$-ter-TrFE $\mathrm{E}_{0.37}$-ter- $\left.\mathrm{VA}_{0.10}\right)$ shows a large increase in the signals in the region around $212 \mathrm{ppm}$ confirming isotactic TrFE-TrFE linkages.

As expected, $\mathrm{P}\left(\mathrm{VDF}_{0.78}\right.$-ter-TrFE ${ }_{0.17}$-ter- $\left.\mathrm{VA}_{0.05}\right)$ is in the ferroelectric phase at room temperature, as evidenced by the presence of the concomitant (110/200) WAXS peaks located at 14.15 $\mathrm{nm}^{-1}$ (see Fig. 2c). Moreover, peak deconvolution reveals an additional crystalline phase at $13.7 \mathrm{~nm}^{-1}$, which is recognized as a defective ferroelectric phase having gauche defects. ${ }^{44,45}$ In contrast, as DSC and FTIR spectroscopy already suggested, $\mathrm{P}\left(\mathrm{VDF}_{0.53}\right.$-ter-TrFE ${ }_{0.37}$-ter- $\left.\mathrm{VA}_{0.10}\right)$ shows a completely different crystallization behavior. In the WAXS profile depicted in Fig. 2d, the coexistence of two crystalline phases characterized by two different peaks located at 13.24 and $13.48 \mathrm{~nm}^{-1}$ is revealed. Next to the characteristic ferroelectric phase peak located at $13.48 \mathrm{~nm}^{-1}$, a second peak located at $13.24 \mathrm{~nm}^{-1}$ is present and it is associated with the existence of a disordered paraelectric structure, in agreement with many literature reports. ${ }^{20,46-49}$ The large shift to lower $q$-values in $\mathrm{P}\left(\mathrm{VDF}_{0.53}\right.$-ter-TrFE $\mathrm{T}_{0.37}$-ter- $\left.\mathrm{VA}_{0.10}\right)$ is attributed to the inclusion of more TrFE units increasing the spacing between the reflective planes. Additionally, since the $100 \%$ melting enthalpies are unknown, WAXS is used here to determine the crystallinity of the terpolymers. Interestingly, an increasing trend is observed upon a higher TrFE content in the 
fluorinated VA-based polymer samples. From a previous study, $\mathrm{P}(\mathrm{VDF}-\mathrm{co}$-VA) shows a degree of crystallinity of $38 \%$, whereas the crystallinity of $\mathrm{P}\left(\mathrm{VDF}_{0.78}\right.$-ter-TrFE ${ }_{0.17}$-ter- $\left.\mathrm{VA}_{0.05}\right)$ and $\mathrm{P}\left(\mathrm{VDF}_{0.53^{-}}\right.$ ter-TrFE $\mathrm{E}_{0.37}$-ter- $\mathrm{VA}_{0.10}$ ) is calculated to be $48 \%$ and $63 \%$, respectively. ${ }^{28}$ We believe that the increasing size of TrFE monomers overcomes structural imperfections induced by VA units allowing more VA to be included in the crystal lattices. Noteworthily, in the VA-based terpolymers, similar or higher degrees of crystallinities are obtained as compared to $\mathrm{P}\left(\mathrm{VDF}_{53^{-}}\right.$ co-TrFE $\left.{ }_{47}\right), \mathrm{P}(\mathrm{VDF}$-ter-TrFE-ter-CTFE) and $\mathrm{P}$ (VDF-ter-TrFE-terCFE) that demonstrate appealing electroactive behaviors for dielectric applications..$^{\mathbf{8 , 2 0 , 4 1}}$

One major advantage of the P(VDF-ter-TrFE-ter-VA) terpolymers is having an easily accessible hydroxyl functional group that allows facile modifications. Using the group for crosslinking offers an opportunity to break up large ferroelectric crystalline domains so that slim hysteresis loops can be obtained, while still having high polarizations..$^{5,7,8}$ Due to its high degree of crystallinity and crystalline phases beneficial for energy storage applications, we chose to crosslink $\mathrm{P}\left(\mathrm{VDF}_{0.53}\right.$-ter-TrFE $\mathrm{E}_{0.37}$-ter- $\left.\mathrm{VA}_{0.10}\right)$ using hexamethylene diisocyanate (HMDI) with 0.1-, 0.25- and 0.5-fold excess of isocyanate to hydroxyl groups. The crosslinked fluorinated networks are named according to the isocyanate excess used, namely
$\mathrm{P}\left(\mathrm{VDF}_{0.53}\right.$-ter-TrFE $\mathrm{E}_{0.37}$-ter- $\left.\mathrm{VA}_{0.10}\right)$-0.1 $\times, \quad \mathrm{P}\left(\mathrm{VDF}_{0.53}\right.$-ter-TrFE $\mathrm{T}_{0.37^{-}}$ ter- $\left.\mathrm{VA}_{0.10}\right)-0.25 \times$ and $\mathrm{P}\left(\mathrm{VDF}_{0.53}\right.$-ter-TrFE $\mathrm{E}_{0.37}$-ter- $\left.\mathrm{VA}_{0.10}\right)-0.5 \times$.

As expected, the crosslinked fluoropolymers are insoluble in common organic solvents, such as dimethylformamide, proving their crosslinked nature. In addition, the FTIR spectra, shown in Fig. 3a, demonstrate the formation of urethane bonds as indicated by the appearance of the carbamate absorption band at $1525 \mathrm{~cm}^{-1}$ and the carbonyl stretching at $1704 \mathrm{~cm}^{-1}$. Moreover, no grafting of the $\mathrm{P}\left(\mathrm{VDF}_{0.53}\right.$-ter-TrFE $\mathrm{E}_{0.37}$-ter- $\left.\mathrm{VA}_{0.10}\right)$ terpolymers occurred, which is demonstrated by the absence of the asymmetric stretching of isocyanate groups expected to be at around $2277 \mathrm{~cm}^{-1}$. $^{0}$

The crystalline phases of the crosslinked terpolymers are analyzed using FTIR spectroscopy and WAXS, and the results are shown in Fig. 3. As expected, the crystallization behavior is drastically changed upon crosslinking. The crystallinity of crosslinked $\quad \mathrm{P}\left(\mathrm{VDF}_{0.53}\right.$-ter-TrFE $\mathrm{T}_{0.37}$-ter- $\left.\mathrm{VA}_{0.10}\right)$ terpolymers reduces significantly with increasing the use of the crosslinking agent as shown in Table 1. Nevertheless, peak deconvolution of the WAXS profiles reveals that the fraction of disordered paraelectric phase in the crosslinked samples progressively increases when the amount of crosslinking agent is increased. This is supported by analysis of the FTIR spectra, where the absorption band at $506 \mathrm{~cm}^{-1}$ corresponding to the TTTG
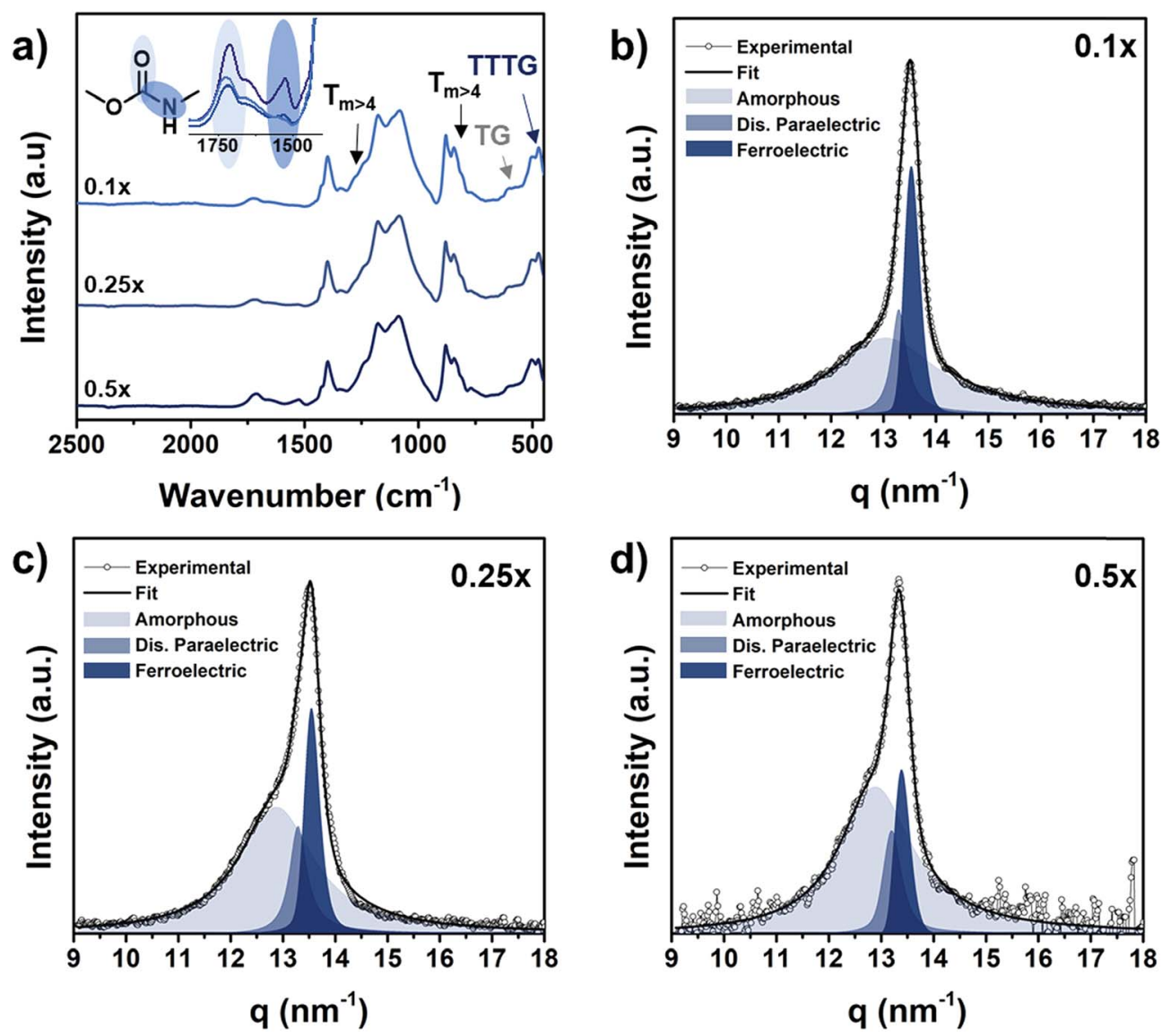

Fig. 3 (a) FTIR spectra of the crosslinked P(VDF 0.53 -ter-TrFE 0.37 -ter-VA $\left.A_{0.10}\right)$ terpolymers. WAXS profiles of (b) $P\left(V_{D} F_{0.53}-t e r-T r F E_{0.37}-t e r-V A_{0.10}\right)$ $0.1 \times$, (c) $P\left(V_{D F} F_{0.53}\right.$-ter-TrFE $E_{0.37}$-ter-VA $\left.\mathrm{A}_{0.10}\right)-0.25 \times$ and (d) $P\left(V_{D F} F_{0.53}\right.$-ter-TrFE $E_{0.37}$-ter- $\left.V A_{0.10}\right)-0.5 \times$. The crosslinked fluorinated networks are named according to the excess of isocyanate groups used compared to the VA groups in the terpolymer backbone. 
Table 1 Crystallization characteristics of the polymers used in this study

\begin{tabular}{|c|c|c|c|c|c|c|c|}
\hline Polymer & $X_{\mathrm{c}}^{a}(\%)$ & $F_{\text {para }}^{b}$ & $F_{\text {ferro }}{ }^{c}$ & $\mathrm{FWHM}_{\mathrm{p}}{ }^{d}\left(\mathrm{~nm}^{-1}\right)$ & $\mathrm{FWHM}_{\mathrm{f}}{ }^{e}\left(\mathrm{~nm}^{-1}\right)$ & $d_{\text {para }}^{f}(\mathrm{~nm})$ & $d_{\text {ferro }}{ }^{g}(\mathrm{~nm})$ \\
\hline $\mathrm{P}\left(\mathrm{VDF}_{0.53}-\mathrm{TrFE}_{0.37}-\mathrm{VA}_{0.10}\right)$ & 63 & 0.30 & 0.70 & 0.18 & 0.35 & 34.9 & 18.0 \\
\hline $\mathrm{P}\left(\mathrm{VDF}_{0.53}-\mathrm{TrFE}_{0.37}-\mathrm{VA}_{0.10}\right)-0.1 \times$ & 38 & 0.37 & 0.63 & 0.34 & 0.35 & 18.5 & 18.0 \\
\hline $\mathrm{P}\left(\mathrm{VDF}_{0.53}-\mathrm{TrFE}_{0.37}-\mathrm{VA}_{0.10}\right)-0.5 \times$ & 26 & 0.48 & 0.52 & 0.42 & 0.35 & 15.0 & 18.0 \\
\hline
\end{tabular}

${ }^{a}$ Degree of crystallinity calculated from the WAXS profiles. ${ }^{b}$ Volume fraction of disordered paraelectric phase. ${ }^{c}$ Fraction of ferroelectric phase. ${ }^{d}$ Full width half maximum of the disordered paraelectric. ${ }^{e}$ Full width half maximum of the ferroelectric phase. ${ }^{f}$ Crystallite size calculated using the Scherrer equation of the disordered paraelectric phase. ${ }^{g}$ Crystallite size calculated using the Scherrer equation of the ferroelectric phase.

Table 2 Maximum and remanent polarization of the (crosslinked) P(VDF-ter-TrFE-ter-VA) terpolymers used

\begin{tabular}{lllll}
\hline Polymer & $\begin{array}{l}P_{\text {max }} \\
(\mu \mathrm{C} \mathrm{cm}\end{array}$ & $\begin{array}{l}\left.P_{\text {rem }}\right) \\
\left(\mu \mathrm{C} \mathrm{cm}{ }^{-2}\right)\end{array}$ & $\begin{array}{l}\text { Field } \\
\left(\mathrm{MV} \mathrm{m}^{-1}\right)\end{array}$ & $\varepsilon_{\text {app }}$ \\
\hline $\mathrm{P}\left(\mathrm{VDF}_{0.78}-\mathrm{TrFE}_{0.17}-\mathrm{VA}_{0.05}\right)$ & 7.13 & 3.10 & 250 & \\
$\mathrm{P}\left(\mathrm{VDF}_{0.53}-\mathrm{TrFE}_{0.37}-\mathrm{VA}_{0.10}\right)$ & 5.52 & 1.01 & 250 & 45.3 \\
$\mathrm{P}\left(\mathrm{VDF}_{0.53}-\mathrm{TrFE}_{0.37}-\mathrm{VA}_{0.10}\right)-0.1 \times$ & 4.54 & 0.37 & 260 & 30.6 \\
$\mathrm{P}\left(\mathrm{VDF}_{0.53}-\mathrm{TrFE}_{0.37}-\mathrm{VA}_{0.10}\right)-0.25 \times$ & 4.05 & 0.25 & 260 & 20.7 \\
$\mathrm{P}\left(\mathrm{VDF}_{0.53}-\mathrm{TrFE}_{0.37}-\mathrm{VA}_{0.10}\right)-0.5 \times$ & 3.45 & 0.15 & 260 & 16.4 \\
& & & & \\
\hline
\end{tabular}

conformation becomes more pronounced, while the bands showing the $\mathrm{T}_{\mathrm{m}>4}$ conformations reduce in intensity. Moreover, crosslinking reduces the crystallite size of the disordered paraelectric crystals in the terpolymers from $34.9 \mathrm{~nm}$ for pristine $\mathrm{P}\left(\mathrm{VDF}_{0.53}\right.$-ter-TrFE $\mathrm{E}_{0.37}$-ter- $\left.\mathrm{VA}_{0.10}\right)$ to just $15.0 \mathrm{~nm}$ for $\mathrm{P}\left(\mathrm{VDF}_{0.53}\right.$-ter-TrFE ${ }_{0.37}$-ter- $\left.\mathrm{VA}_{0.10}\right)$ crosslinked with 0.5 -fold excess of HMDI. Due to the well-distributed crosslinking sites in the fluorinated networks, only small disordered paraelectric crystals are formed, separated by chemical crosslinks. This reduction in the average disordered paraelectric crystallite size is well evidenced by the increase in the peak width with increasing crosslinking observed by WAXS (Table 1). In the literature, a similar crystal size reduction is also observed in crosslinking of $\mathrm{P}$ (VDF- $\mathrm{Co}$-CTFE), while other crosslinking methods, such as electrobeam irradiation, offer poor control over the crosslinking site, resulting in a large distribution of crystallite sizes. ${ }^{24,51}$
To compare the electroactive behavior of the (crosslinked) terpolymers, displacement-electric field (D-E) measurements are performed by applying an electric field in a triangular wave form at a frequency of $10 \mathrm{~Hz}$, measuring the polarization as the integral of the resulting current. At lower electric fields $(<80 \mathrm{MV}$ $\mathrm{m}^{-1}$ ), the (crosslinked) terpolymers show linear dielectric behavior (ESI $\dagger$ ). Consequently, by calculating the stored energy density and using eqn (1), the apparent dielectric constant can be derived. ${ }^{52,53}$ It is found that $\mathrm{P}\left(\mathrm{VDF}_{0.78}\right.$-ter-TrFE $\mathrm{T}_{0.17}$-ter- $\left.\mathrm{VA}_{0.05}\right)$ and $\mathrm{P}\left(\mathrm{VDF}_{0.53}\right.$-ter-TrFE $\mathrm{T}_{0.37}$-ter- $\left.\mathrm{VA}_{0.10}\right)$ show an apparent dielectric constant $\left(\varepsilon_{\text {app }}\right)$ of 20 and 45 , respectively, while it is progressively reducing for the crosslinked samples due to the lower degree of crystallinity (Table 2). At higher electric fields $\left(250 \mathrm{MV} \mathrm{m}^{-1}\right)$, the ferroelectric dipoles align in $\mathrm{P}\left(\mathrm{VDF}_{0.78}\right.$-ter$\mathrm{TrFE}_{0.17}$-ter- $\mathrm{VA}_{0.05}$ ) leading to a polarization of $7.13 \mu \mathrm{C} \mathrm{cm}^{-2}$ and a remanent polarization of $3.10 \mu \mathrm{C} \mathrm{cm}^{-2}$ (ESI $\dagger$ ). The relatively low remanent polarization of $\mathrm{P}\left(\mathrm{VDF}_{0.78}\right.$ ter-TrFE $\mathrm{T}_{0.17}$-ter- $\left.\mathrm{VA}_{0.05}\right)$ compared to ferroelectric $\mathrm{P}(\mathrm{VDF}-\mathrm{co}$-TrFE) copolymers can be ascribed to the formation of physical pinning spots enhancing the dipole reversibility. ${ }^{5,8,28}$ In Fig. 4 , the $\mathrm{D}-\mathrm{E}$ loops of $\mathrm{P}\left(\mathrm{VDF}_{0.53^{-}}\right.$ ter-TrFE ${ }_{0.37}-$ ter- $\mathrm{VA}_{0.10}$ ) and the fluorinated networks are depicted at similar electric fields. Here, relaxor ferroelectric behavior is observed in all samples. Due to VA pinning spots in the nanocrystals and the mixture of disordered paraelectric and ferroelectric phases, $\mathrm{P}\left(\mathrm{VDF}_{0.53}\right.$-ter-TrFE $\mathrm{T}_{0.37}-$ ter- $\left.\mathrm{VA}_{0.10}\right)$ demonstrates a low remanent polarization of $1.01 \mu \mathrm{C} \mathrm{cm}-2$ and a maximum polarization of $5.52 \mu \mathrm{C} \mathrm{cm}^{-2}$ at $250 \mathrm{MV} \mathrm{m}^{-1}$. This
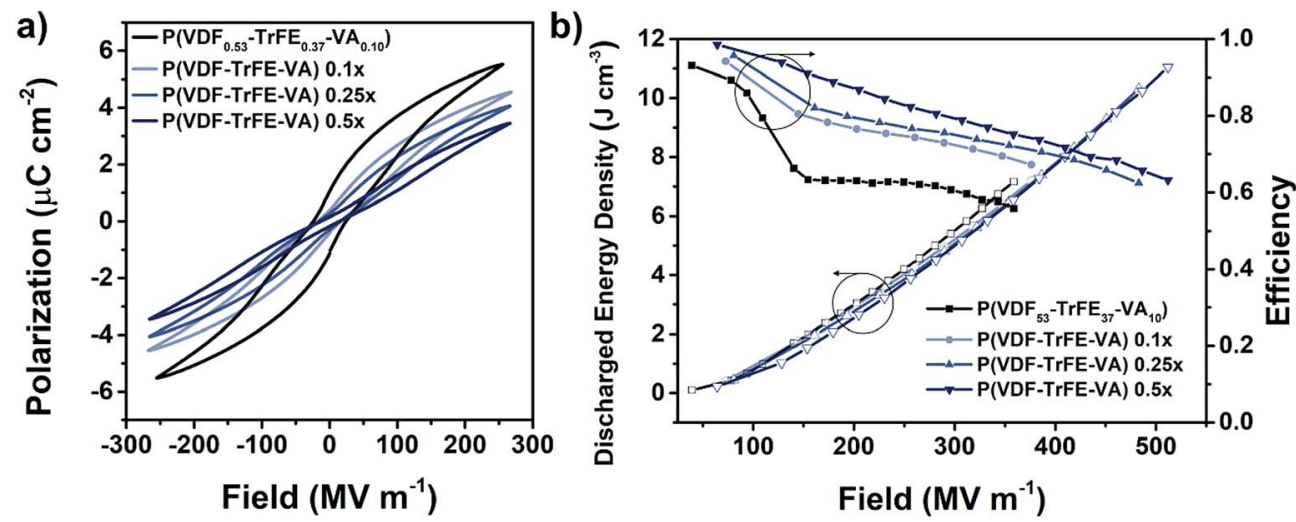

Fig. 4 (a) $\mathrm{D}$-E loops of $\mathrm{P}\left(\mathrm{VDF}_{0.53}\right.$-ter-TrFE $\mathrm{E}_{0.37}$-ter- $\left.\mathrm{VA}_{0.10}\right)$ and the crosslinked terpolymers showing the narrow hysteresis loops due to physical pinning and chemical crosslinking. (b) The discharge energy densities and charge-discharge efficiencies of $P\left(V_{D} F_{0.53}-t e r-T r F E_{0.37}-t e r-V A_{0.10}\right)$ and the crosslinked terpolymers. 
relaxor ferroelectric behavior shows great similarity with results obtained for other relaxor ferroelectric terpolymers. ${ }^{5,8,20,41}$ For example, comparable to $\mathrm{P}(\mathrm{VDF}$-ter-TrFE-ter-CFE $), \mathrm{P}\left(\mathrm{VDF}_{0.53}\right.$-ter$\mathrm{TrFE}_{0.37}$-ter- $\left.\mathrm{VA}_{0.10}\right)$ demonstrates a charge-discharge efficiency of $65 \%$ at $150 \mathrm{MV} \mathrm{m}^{-1} .{ }^{54}$ Unfortunately, currently available relaxor ferroelectric terpolymers suffer from large ferroelectric losses at higher fields. To mitigate these concerns and to consequently enhance the charge-discharge efficiency, while maintaining the large discharge energy densities, ferroelectric crystals are required to be well isolated., ${ }^{5,14}$ The crosslinking method of relaxor ferroelectric polymers introduced in this work appears to be very promising. Even though the reduction in crystallinity and increase in the amount of crystals in the disordered paraelectric phase lower the maximum polarization of the crosslinked fluorinated terpolymers, the remanent polarization is also reduced significantly due to better isolation of ferroelectric domains by chemical crosslinking. ${ }^{5}$ As such, the $\mathrm{P}\left(\mathrm{VDF}_{0.53}\right.$-ter-TrFE $\mathrm{T}_{0.37}$-ter- $\left.\mathrm{VA}_{0.10}\right)-0.5 \times$ shows a maximum polarization of $3.45 \mu \mathrm{C} \mathrm{cm}^{-2}$ and remanent polarization as low as $0.15 \mu \mathrm{C} \mathrm{cm}^{-2}$ at $260 \mathrm{MV} \mathrm{m}^{-1}$, respectively (Fig. 4 a and Table 2). This leads to increased charge-discharge efficiencies as clearly visualized in Fig. 4b. For example, at $150 \mathrm{MV} \mathrm{m}^{-1}, \mathrm{P}\left(\mathrm{VDF}_{0.53}\right.$-ter$\mathrm{TrFE}_{0.37}$-ter- $\mathrm{VA}_{0.10}$ ) shows an efficiency of $63 \%$, while this is increased to $82 \%$ for $\mathrm{P}\left(\mathrm{VDF}_{0.53}\right.$-ter-TrFE $\mathrm{T}_{0.37}$-ter $\left.-\mathrm{VA}_{0.10}\right)-0.25 \times$, while both have a discharge energy density of $2 \mathrm{~J} \mathrm{~cm}^{-3}$. Since these materials show great promise for capacitive energy storage applications, future work should be devoted to exploring the full potential of $\mathrm{P}(\mathrm{VDF}-$ ter-TrFE-ter-VA) terpolymers, including optimization of the composition of the terpolymers, choice of the crosslinking agent and to gain better insights into the high field dielectric loss and failure mechanisms.

\section{Conclusions}

In this work, we have demonstrated the synthesis and crosslinking of a novel class of relaxor ferroelectric PVDF-based terpolymers containing VA units. The introduction of VA units in the terpolymer backbone drastically changed its crystallization behavior and leads to a reduction of the Curie transition temperature compared to $\mathrm{P}(\mathrm{VDF}-\mathrm{co}$-TrFE) copolymer analogues. The $\mathrm{P}\left(\mathrm{VDF}_{0.78}\right.$-ter-TrFE ${ }_{0.17}$-ter- $\left.\mathrm{VA}_{0.05}\right)$ having a relatively low content of TrFE and VA crystallizes in the ferroelectric phase and demonstrate ferroelectric behavior. In contrast, pristine $\mathrm{P}\left(\mathrm{VDF}_{0.53}\right.$-ter-TrFE $\mathrm{T}_{0.37}$-ter- $\left.\mathrm{VA}_{0.10}\right)$ crystallizes in a mixture of the ferroelectric and disordered paraelectric phases resulting in narrow hysteresis behavior with a maximum and remanent polarization of $5.52 \mu \mathrm{C} \mathrm{cm}^{-2}$ and $1.01 \mu \mathrm{C} \mathrm{cm}^{-2}$, respectively. In addition, chemical crosslinking of $\mathrm{P}\left(\mathrm{VDF}_{0.53}\right.$-ter-TrFE $\mathrm{T}_{0.37}$-ter$\mathrm{VA}_{0.10}$ ) terpolymers using urethane chemistry promotes the crystallization in the disordered paraelectric phase and the formation of small nanocrystals giving ultra slim hysteresis loops with remanent polarizations as low as $0.15 \mu \mathrm{C} \mathrm{cm}$. The low remanent polarization leads to increased efficiencies for the terpolymers due to a reduction of ferroelectric loss, while maintaining similar discharge energy densities. Since crosslinking relaxor ferroelectric polymers show great promise for capacitive energy storage applications, especially due to the large increase in efficiencies, future work should be devoted to exploring the full potential of VA-containing terpolymers, including optimization of the composition of the terpolymers and gain insights into the dielectric loss and failure mechanisms.

\section{Conflicts of interest}

There are no conflicts to declare.

\section{Acknowledgements}

The research was supported by an NWO-VICI innovational research grant. A. J. J. Woortman is kindly acknowledged for the GPC measurements.

\section{References}

1 H. Bluhm, Pulsed Power Systems: Principles and Applications, Springer-Verlag, Berlin Heidelberg, 2006.

2 I. Husain, Electric and Hybrid Vehicles: Design Fundamentals, CRC Press, Boca Raton, FL, 2 edn, 2010.

3 R. Teodorescu, M. Liserre and P. Rodríguez, Grid Converters for Photovoltaic and Wind Power Systems, Wiley-Blackwell, 2010.

4 A. J. Lovinger, Science, 1983, 220, 1115-1121.

5 L. Zhu and Q. Wang, Macromolecules, 2012, 45, 2937-2954.

6 W. Li, Q. Meng, Y. Zheng, Z. Zhang, W. Xia and Z. Xu, Appl. Phys. Lett., 2010, 96, 192905.

7 F. Guan, L. Yang, J. Wang, B. Guan, K. Han, Q. Wang and L. Zhu, Adv. Funct. Mater., 2011, 21, 3176-3188.

8 L. Yang, X. Li, E. Allahyarov, P. L. Taylor, Q. M. Zhang and L. Zhu, Polymer, 2013, 54, 1709-1728.

9 N. L. Meereboer, I. Terzić, S. Saidi, D. Hermida Merino and K. Loos, ACS Macro Lett., 2018, 863-867.

10 I. Terzic, N. L. Meereboer and K. Loos, Polym. Chem., 2018, 9, 3714-3720.

11 V. S. D. Voet, G. ten Brinke and K. Loos, J. Polym. Sci., Part A: Polym. Chem., 2014, 52, 2861-2877.

12 V. S. D. Voet, G. O. R. A. van Ekenstein, N. L. Meereboer, A. H. Hofman, G. ten Brinke and K. Loos, Polym. Chem., 2014, 5, 2219-2230.

13 V. S. D. Voet, M. Tichelaar, S. Tanase, M. C. MittelmeijerHazeleger, G. ten Brinke and K. Loos, Nanoscale, 2012, 5, 184-192.

14 I. Terzić, N. L. Meereboer, M. Acuautla, G. Portale and K. Loos, Nat. Commun., 2019, DOI: 10.1038/s41467-01908436-2.

15 T. Soulestin, V. Ladmiral, F. D. Dos Santos and B. Améduri, Prog. Polym. Sci., 2017, 72, 16-60.

16 H. Xu, Z.-Y. Cheng, D. Olson, T. Mai, Q. M. Zhang and G. Kavarnos, Appl. Phys. Lett., 2001, 78, 2360-2362.

17 H.-M. Bao, J.-F. Song, J. Zhang, Q.-D. Shen, C.-Z. Yang and Q. M. Zhang, Macromolecules, 2007, 40, 2371-2379.

18 B. Neese, B. Chu, S.-G. Lu, Y. Wang, E. Furman and Q. M. Zhang, Science, 2008, 321, 821-823. 
19 Y. Lu, J. Claude, B. Neese, Q. Zhang and Q. Wang, J. Am. Chem. Soc., 2006, 128, 8120-8121.

20 Y. Liu, H. Aziguli, B. Zhang, W. Xu, W. Lu, J. Bernholc and Q. Wang, Nature, 2018, 562, 96-100.

21 Y. Li, T. Soulestin, V. Ladmiral, B. Ameduri, T. Lannuzel, F. Domingues Dos Santos, Z.-M. Li, G.-J. Zhong and L. Zhu, Macromolecules, 2017, 50, 7646-7656.

22 J. Li, X. Hu, G. Gao, S. Ding, H. Li, L. Yang and Z. Zhang, J. Mater. Chem. C, 2013, 1, 1111-1121.

23 J. Li, H. Gong, Q. Yang, Y. Xie, L. Yang and Z. Zhang, Appl. Phys. Lett., 2014, 104, 263901.

24 P. Khanchaitit, K. Han, M. R. Gadinski, Q. Li and Q. Wang, Nat. Commun., 2013, 4, 2845.

25 S. Tan, J. Li, G. Gao, H. Li and Z. Zhang, J. Mater. Chem., 2012, 22, 18496-18504.

26 Q. M. Zhang, V. Bharti and X. Zhao, Science, 1998, 280, 21012104.

27 Y. J. Shin, R. H. Kim, H. J. Jung, S. J. Kang, Y. J. Park, I. Bae and C. Park, ACS Appl. Mater. Interfaces, 2011, 3, 4736-4743.

28 N. L. Meereboer, I. Terzić, P. van der Steeg, M. Acuautla, V. S. D. Voet and K. Loos, Materials Today Energy, 2019, 11, 83-88.

29 W. Bras, I. P. Dolbnya, D. Detollenaere, R. van Tol, M. Malfois, G. N. Greaves, A. J. Ryan, E. Heeley and IUCr, J. Appl. Crystallogr., 2003, 36, 791-794.

30 M. Borsboom, W. Bras, I. Cerjak, D. Detollenaere, D. Glastra van Loon, P. Goedtkindt, M. Konijnenburg, P. Lassing, Y. K. Levine, B. Munneke, M. Oversluizen, R. van Tol and E. Vlieg, J. Synchrotron Radiat., 1998, 5, 518-520.

31 T. Furukawa, Adv. Colloid Interface Sci., 1997, 71-72, 183208.

32 M. L. Hallensleben, in Ullmann's Encyclopedia of Industrial Chemistry, American Cancer Society, 2000.

33 A. D. Asandei, O. I. Adebolu and C. P. Simpson, J. Am. Chem. Soc., 2012, 134, 6080-6083.

34 T. Soulestin, V. Ladmiral, T. Lannuzel, F. Domingues Dos Santos and B. Ameduri, Macromolecules, 2015, 48, 78617871.

35 J. Brandrup, E. H. Immergut and E. A. Grulke, Polymer Handbook, 4th edn, Wiley, 2004.
36 V. Panchalingam and J. R. Reynolds, J. Polym. Sci., Part C: Polym. Lett., 1989, 27, 201-208.

37 T. Yagi, M. Tatemoto and J. Sako, Polym. J., 1980, 12, 209223.

38 R. Gregorio and M. M. Botta, J. Polym. Sci., Part B: Polym. Phys., 1998, 36, 403-414.

39 K. J. Kim, G. B. Kim, C. L. Vanlencia and J. F. Rabolt, J. Polym. Sci., Part B: Polym. Phys., 1994, 32, 2435-2444.

40 Z. Zhang, Q. Meng and T. C. M. Chung, Polymer, 2009, 50, 707-715.

41 M. R. Gadinski, Q. Li, G. Zhang, X. Zhang and Q. Wang, Macromolecules, 2015, 48, 2731-2739.

42 R. J. Klein, J. Runt and Q. M. Zhang, Macromolecules, 2003, 36, 7220-7226.

43 R. R. Kolda and J. B. Lando, J. Macromol. Sci., Part B: Phys., 1975, 11, 21-39.

44 F. Bargain, P. Panine, F. Domingues Dos Santos and S. Tencé-Girault, Polymer, 2016, 105, 144-156.

45 K. Tashiro and M. Kobayashi, Phase Transitions, 1989, 18, 213-246.

46 G. T. Davis, T. Furukawa, A. J. Lovinger and M. G. Broadhurst, Macromolecules, 1982, 15, 329-333.

47 A. J. Lovinger, G. T. Davis, T. Furukawa and M. G. Broadhurst, Macromolecules, 1982, 15, 323-328.

48 K. Tashiro, K. Takano, M. Kobayashi, Y. Chatani and H. Tadokoro, Polymer, 1984, 25, 195-208.

49 E. Bellet-Amalric and J. F. Legrand, Eur. Phys. J. B, 1998, 3, 225-236.

50 M. Krumova, D. López, R. Benavente, C. Mijangos and J. M. Pereña, Polymer, 2000, 41, 9265-9272.

51 A. Taguet, B. Ameduri and B. Boutevin, in Crosslinking in Materials Science, Springer Berlin Heidelberg, Berlin, Heidelberg, 2005, pp. 127-211.

52 B. Chu, X. Zhou, K. Ren, B. Neese, M. Lin, Q. Wang, F. Bauer and Q. M. Zhang, Science, 2006, 313, 334-336.

53 L. Zhu, J. Phys. Chem. Lett., 2014, 5, 3677-3687.

54 L. Yang, B. A. Tyburski, F. D. Dos Santos, M. K. Endoh, T. Koga, D. Huang, Y. Wang and L. Zhu, Macromolecules, 2014, 47, 8119-8125. 